\title{
Gaining insight into the implementation of an e-learning smoking cessation course in Latin American countries
}

\author{
Ana Vides-Porras ${ }^{1}$, Paula Cáceres ${ }^{2, \dagger}$, Assumpta Company ${ }^{3}$, Olga Guillen ${ }^{3}$, \\ Martha Alicia Arrien ${ }^{4}$, Yolanda Castellano ${ }^{5,6}$, Mercè Margalef ${ }^{5,6}$, \\ Wendy Yantuche ${ }^{7}$, Esteve Fernández ${ }^{5,6,8,9}$, and Cristina Martínez ${ }^{5,6,9,10,11, *}$; \\ the Group of Hospital Coordinators in the Fruitful Project
}

${ }^{1}$ School of Social Sciences, Universidad del Valle de Guatemala, 18 Av. 11-95 zona 15 Vista Hermosa III, Guatemala 01015, Guatemala, ${ }^{2}$ Radiation Oncology Department, Instituto de Cancerología y Hospital Dr. Bernardo del Valle S., 6 Av 6-58 Z-11, Guatemala, ${ }^{3}$ E-oncologia Unit, Institut Català d'Oncologia-ICO, Av. Granvia de L'Hospitalet 199-203, 08908 L'Hospitalet de Llobregat, Barcelona, Spain, ${ }^{4}$ Instituto Oncologico del Oriente Boliviano de Santa Cruz de la Sierra Av. Marcelo Terceros Bánzer, Santa Cruz de la Sierra, Bolivia, ${ }^{5}$ Tobacco Control Unit, Cancer Control and Prevention Programme, Institut Català d'Oncologia-ICO 08907, ${ }^{6}$ Cancer Control and Prevention Group, Institut d'Investigació Biomèdica de Bellvitge-IDIBELL, Av. Granvia de L'Hospitalet 199-203, 08908 L'Hospitalet de Llobregat, Barcelona, Spain, ${ }^{7}$ Oncologic Surgery, Instituto de Cancerología y Hospital Dr. Bernardo del Valle S, Guatemala, ${ }^{8}$ Department of Clinical Sciences, School of Medicine, Universitat de Barcelona, C. Feixa llarga s/n, 08907, ${ }^{9}$ Consortium for Biomedical Research in Respirarory Diseases (CIBER en Enfermedades Respiratorias, CIBERES), Madrid, Spain, ${ }^{10}$ Department of Nursing: Public Health, Mental Health and Maternal and Child Health, Faculty of Medicine and Health Sciences, Universitat de Barcelona, L'Hospitalet del Llobregat, Barcelona, Spain and ${ }^{11}$ Philip R. Lee Institute for Health Policy Studies, University of California San Francisco, 3333 California St., Ste. 265, San Francisco, CA 94118, USA

*Corresponding author. E-mail: cmartinez@iconcolgia.net

${ }^{\dagger}$ Deceased.

\section{Summary}

Continuous medical education focused on health problems emerging in low- and middle-income countries (LMICs) is scarce. Although tobacco consumption is increasing in LMICs, there is a lack of tobacco cessation training programs in these countries. To promote smoking cessation interventions in Bolivia, Guatemala and Paraguay, we adapted an e-learning program developed in Catalonia (Spain). This process evaluation study reports on reach, dose and satisfaction of participants with the course, as well as the contextual factors of its application. We conducted a multiple method evaluation, which included a survey and several focus groups, each one specific to the same type of healthcare professional (nurses, doctors, other professionals). Two hundred and ninety-two participants registered into the online course. The motivation for undertaking the course was different between doctors and nurses. The main sources of difficulty in enrolling and finishing the course were the 
technical problems experienced when accessing the platform, and lack of acquaintance with computers and the Internet in general. Our results show that implementing e-learning education in hospitals from LMICs is feasible, especially when there are similarities between participating countries and the country in which the original program was developed. However, several elements such as strong organizational commitment, technical support and resources and adequate communication channels should be provided to facilitate enrollment and training completion. Efforts to improve Internet access should be made to avoid jeopardizing students' motivation to enroll and complete online training.

Key words: training, e-learning, distant learning, tobacco, low- and middle-income countries

\section{INTRODUCTION}

During the last decades, the tobacco epidemic has fallen in many developed countries thanks to the application of several policies embraced by the World Health Organization (WHO) Framework Convention on Tobacco Control (FCTC) (WHO, 2013). However, tobacco use has risen in middle- and low-income countries including the Latin American and Caribbean (LAC) region (Mayor, 2009). Currently, more than 120 million smokers live in these countries (Muller and Wehbe, 2008); half of them will develop a tobacco-related disease, and consequently, they will require medical care (Zack, 2002).

In the LAC region, smoking rates vary by country, sex and socio-economic status (Tong et al., 2011; OPS, 2014). In some low-income countries, however, such as Bolivia, Guatemala and Paraguay, smoking rates are $10 \%$ higher than the rest of LAC countries (PoncianoRodriguez, 2010). Thus, among men, smoking prevalence ranges from $42 \%$ (in Bolivia) to $22.0 \%$ (in Guatemala) (WHO, 2011).

Bolivia, Guatemala and Paraguay signed the WHO FCTC early on, and have implemented some tobacco control measures, including smoke-free legislation (according to the WHO FCTC Article 8). However, smoking cessation services (Article 14) have not received the same recognition and attention (OPS, 2014). Smoking cessation interventions are hardly available (Toll et al., 2014), while the most common barriers to incorporating tobacco cessation interventions into hospitals involve lack of training, expertise and time (Ponciano-Rodriguez, 2010).

Most doctors and nurses report that they have not received formal training in smoking cessation during undergraduate nor graduate education (Bello et al., 2004). Previous research has demonstrated the value of training in increasing the likelihood of assisting patients in quitting (Carson et al., 2012). These training programs obtain higher impact and sustainability when they are fostered by organizations that allocate time, promote key champions and provide implementation materials and resources (Campbell et al., 2011).
Online courses allow distance e-learning, are more costefficient, and provide different teaching opportunities in resource-limited environments (Abutarbush et al. 2006; Aggarwal et al., 2011) by reducing inequalities in access to training and strengthening professional teams in addressing different health concerns (Salinas et al., 2017). In the last decade, e-learning in the healthcare sector has become one of the most prolific continuous education initiatives (Cheng et al., 2014). Moreover, previous online tobacco cessation training courses have demonstrated an increase in health providers' skills in counseling patients on tobacco cessation (Schmelz et al., 2010; Carson et al., 2012; Gordon et al., 2013). Although there are several e-learning tobacco cessation training programs, the majority have been developed and evaluated in Anglo-Saxon countries (Selby et al., 2015). There are still limited reports of provision of distance e-learning programs in LAC, and a recent study has shown significant gaps in the use of mobile technologies for training in these countries (Winters et al., 2019).

Implementing previously designed programs can save time and money while increasing the likelihood of achieving successful outcomes (Kassel and Ross 2005; Card et al., 2011). E-learning smoking cessation training programs can be modified to fit local necessities (Sarna et al., 2014). However, to our knowledge, no previous e-learning smoking cessation training programs have been adapted to the reality of LAC and no evaluations about factors that facilitate and hinder them have been conducted.

To fill the gap of the lack of tobacco cessation training programs in Spanish speaking LAC countries, we designed the 'Fruitful Project', aimed at adapting and implementing an e-learning program developed in the Catalan Institute of Oncology (ICO) to the reality of healthcare organizations and professionals of three Latin American countries (LACs) (Bolivia, Guatemala and Paraguay) (Martínez et al., 2017a,b).

For the adaptation process, we used the Card's adaptation framework, detecting the mismatches between the original training program and the characteristics of each of the participating countries (Bolivia, Guatemala and 
Paraguay). The adaptation process was devised to tailor the training program to the characteristics of each participating country. The mismatches identified between the 'original' and the 'adapted' versions of the training program/s were reported are listed below (Martínez et al., 2017a,b):

- Language background and literacy level in some of the terms used: The course was in Spanish from Spain, and the Spanish spoken in Bolivia, Guatemala and Paraguay differs somewhat with respect to vocabulary, expressions and to some degree, grammatical structure.

- Description of the epidemiology smoking in Model 1: The original version included information on smoking-related situations in Spain, whereas the adapted version included the most updated data in Bolivia, Guatemala and Paraguay.

- In Module 4, tobacco cessation pharmacological treatment (nicotine replacement therapy, bupropion, varenicline) and settings where tobacco prevention and cessation services are performed in Spain (primary care, hospitals, quit lines, etc.), were adapted to the current resources in each country.

- In case studies, the clinical simulations demonstrate the cultural characteristics of each country.

- Questions and answers of the assessment and evaluation were also changed according to the adapted contents.

Second, we employed the Roger's Diffusion of Innovations Theory to plan the dissemination of the training within the organization. Roger described diffusion of innovations as the process by which an innovation is communicated through certain channels over time among members of a social system (in our case the hospitals) (Rogers, 2003). Because Roger's Theory ponders communication as a key element for disseminating and implementing innovations through the influence of different stakeholders in the system, we gave coordinators, liaisons and other actors an important communication role in our project. In addition, in each country we employed different communication channels (emails, leaflets, word of mouth, etc.) to convey the messages to the staff.

Theoretical framework of the process evaluation To understand the effectiveness and diffusion of an innovation, it is critical to explore the views of the stakeholders, including their perceptions about the innovation, its acceptability, adoption and appropriateness, among other implementation process indicators
(Proctor et al., 2011). Exploring the contextual factors is of vital importance when the innovation is applied in a new context. It has been reported that successful implementation of a new program is associated with its effectiveness (Durlak and DuPre, 2008). Therefore, an evaluation of the implementation process that includes the contextual factors and the view of the stakeholders on the innovation, can facilitate understanding and explaining the results of the program, while providing future directions for its sustainability and dissemination.

Consequently, the goal of this paper is two-fold; first, to evaluate the contextual factors that promote and inhibit undertaking a smoking cessation e-learning training program in low- and middle-income countries (LMICs) in Latin America; and second, to evaluate several implementation outcomes such as the reach, dose, satisfaction and reasons for completing or not completing the course. Given that e-learning has become a new form of higher education, its evaluation needs to undertake a complex approach (Friesen, 2009) in which the elearning program is assessed from different perspectives, including the value of the platform in terms of content and also in terms of the experience of its users. User experience is influenced by many factors that include not only its content, structure and relevance, but also learning styles, preparedness and e-readiness (Brooks et al., 2016). For this reason, we used a multiple method approach in which quantitative and qualitative methods were applied sequentially and used together to reach a comprehensive understanding of the experience of participants in the implementation of an online smoking cessation program (Morse, 2003). The importance of qualitative evaluation lies in its potential to offer insights into the perceptions of value, usefulness and weaknesses held by the users of a given platform. Furthermore, it also allows for a better understanding of the criteria used by these users in the assessment process (Jennifer et al., 2007), providing crucial information for the implementation of similar programs locally and regionally.

\section{MATERIALS}

\section{The e-learning program}

The original program was developed by the online platform e-oncologia (http://www.e-oncologia.org/en/) (Martínez et al., 2017a,b). The final curriculum content of the 'Brief Intervention for Smoking Cessation Training Program' is composed of four modules, and it is customized with specific data for each country. The course provides several materials including slides, online 
Table 1: Characteristics of the participant hospitals

\begin{tabular}{|c|c|c|c|c|}
\hline Hospital & Country & Type of hospital & Workers, $n$ & Beds, $n$ \\
\hline $\begin{array}{l}\text { Instituto Oncológico del Oriente Boliviano } \\
\text { de Santa Cruz de la Sierra }\end{array}$ & Bolivia & Public, urban oncology hospital & 359 & 79 \\
\hline $\begin{array}{l}\text { Instituto de Cancerología y Hospital Dr } \\
\text { Bernardo del Valle }\end{array}$ & Guatemala & University, public, urban oncology hospital & 300 & 108 \\
\hline $\begin{array}{l}\text { Instituto Nacional de Enfermedades } \\
\text { Respiratorias y del Ambiente (INERAM) }\end{array}$ & Paraguay & University, public, respiratory hospital & 746 & 151 \\
\hline
\end{tabular}

tutorials with an expert tutor, recommended readings, patient cessation brochures, a pharmaceutical pocket guideline and an organizational recommendation model to facilitate the implementation of tobacco cessation services in the hospital setting.

\section{Study setting}

The participant hospitals were selected at convenience because they had previously collaborated with the Training Unit of the ICO. The selected specialized hospitals included two oncologic hospitals and one respiratory hospital. Their characteristics are given in Table 1.

\section{Recruitment}

Each local coordinator recruited hospital workers from all units and departments for over 6 months (from September 2015 to March 2016) through informative sessions, leaflets and posters (designed to inform about the training program), and personalized emails. Inclusion criteria included working at the hospital and having an email account.

\section{Procedure}

Program evaluation answers questions about a program's effectiveness, and the results can be used to improve such services. To evaluate the Fruitful Project we applied the conceptual framework for Continuing Medical Education conceived by Moore et al. (Moore et al., 2009, 2015).

\section{Design}

Multiple-method process evaluation (Proctor et al., 2011) with two approaches: (i) for the quantitative approach we conducted an evaluation guided by the essential elements of Moore's framework (Moore et al., 2015) that defined dose or 'completeness for all components' of the training including completion of the course (overall and by modules), participation and results of the evaluation, and satisfaction survey; (ii) for the qualitative approach we conducted several focus groups, each one specific to the same type of healthcare professional (nurses, doctors, other professionals), to assess the personal experiences of the participation, including those who enrolled in the training and finished it, who enrolled into the training and did not finish it, who did not enroll in the training, and those key persons who coordinated the diffusion and enrollment of participants.

\section{Quantitative evaluation}

Quantitatively, we used a questionnaire to gather information on the students' profile (demographics, smoking status and previous training) and a survey after the completion of the course, which evaluated satisfaction and knowledge acquisition (composed of 21 questions).

Variables studied included some process implementation outcomes (Proctor et al., 2011) such as: Reach: We studied the number of participants in each country by sociodemographic characteristics including country, profession (doctors, nurses, other health professionals), sex (men, women), age ( $\leq 35$ years old, $>35$ years old), previous training in smoking cessation (yes, no). Dose: We measured whether students enrolled completed the training overall and by each of the four modules (yes/ no), and the completion of the exam (yes/no). Satisfaction: Every student answered a standardized questionnaire containing nine closed questions and one or two open questions to grasp their satisfaction. The satisfaction aspects explored were: (i) Exhaustive development of contents (introduction, aims, activities, glossary, etc.), (ii) Clarity and rigor of the content; (iii) Diversity of learning activities; (iv) Quality of the evaluation tasks; (v) Quality of the learning methodology employed; (vi) Whether the theoretical and practical content provided allowed transferability to the work setting; (vii) Layout of the online platform (colors and virtualization); (viii) Whether the online platform was easy to navigate and (ix) Whether the learning guidelines included were clear. Questions were presented on a fivepoint Likert-scale, with 5 being 'completely agree' and 1 being 'completely disagree'. 
Analysis

Descriptive analyses were conducted on the demographic data. Main outcome variables were completion of the modules, completion of the pre- and post-test, score on the final exam, dose with the course and level of satisfaction. Furthermore, differences between groups were tested using the Chi-square test. The significant level for all the statistical tests was set at 0.05 .

\section{Qualitative evaluation}

We explored qualitatively the contextual (access) and personal (motivation, previous training) factors that played a role in the process implementation such as acceptability, fidelity, appropriates, and adoption (Proctor et al., 2011). In particular, and due to the fact that the project was conducted in LMICs, we focused our scope on exploring the difficulties associated with access to and completion of the course. This evaluation was carried out by external consultants through a total of eight focus groups in Guatemala (4) and Bolivia (4) $(n=7-9$ persons per group). A total of 62 students participated in the focus groups $($ Guatemala $=28$, Bolivia $=34)$. Due to lack of local professionals to carry out this evaluation, the Paraguay site did not conduct a qualitative evaluation. The main topics considered were content applicability, feasibility of interventions and methodological advantages and disadvantages of the training program. We learned about the participants' experiences in both locations, their preferences and, inhibiting and facilitating factors found throughout the training sessions.

\section{Recruitment and procedure}

Participants for the evaluation were selected by the local coordination teams with whom interviews were held to define the sample and validate the question guide for the focus groups. The same question guide was used on both sites to allow comparison. In both settings, each focus group was composed of the same type of healthcare professional (nurses, doctors, other professionals) to avoid the pressure implicit in participating in a conversation with professionals with higher ranks or status within the institution (e.g. nurses and doctors).

The participation in the focus groups was completely voluntary. However, arrangements had to be made to relieve some of the participants from their daily activities so that they could participate in the 90-min session. All the participants took part in the training process; however, not all of them completed it. All the focus groups were conducted in the hospitals in a separate room. Confidentiality was secured through the allocation of codes to all the participants.
The focus groups in Guatemala were carried out by a moderator and an observer who also took notes regarding the dynamics and turn taking. In Bolivia, besides the moderator, there was an observer and a person taking notes. For all the focus groups, a script in which the researchers introduced themselves, as well as the dynamics, rules for participating and confidentiality matters was followed. The first 5-10 min of each session were used to build rapport and secure consent for audio recording. Session recording began after consent was granted verbally by participants. In the focus group discussions, participants were asked questions assessing the following topics: Means for disseminating the information regarding the course and whether they found them effective; motivation to start and/or complete the course; demotivating factors; methodology usefulness; content pertinence and relevance and suggestions.

\section{Analysis}

The focus groups were transcribed and then analyzed in Spanish through the long table method proposed by Krueger (Krueger, 2015). During this process, the transcribed data was arranged in categories and the information on particular categories was compared among participants to determine the common experiences and themes emerging from the data (Fossey et al., 2002). Given that the study encompassed multiple focus groups, we used constant comparison analysis (Denzin and Lincoln, 2018) to determine if the same themes emerged in different groups. To reduce the researcher bias emerging from having this process performed in two different countries by two different research teams, for this paper, the authors worked with both the final reports from both sites and revised the transcriptions from both sides to verify that the main categories in the report, were present in the transcript. This process aided in determining the level of consensus across groups. The segments of texts presented in the following sections as well as the analysis, were translated into English by the authors.

\section{RESULTS}

\section{Quantitative}

This first Results section describes the reach, dose and satisfaction of the course among participants.

\section{Reach}

Two hundred and ninety-two students registered into the online training; about one-third of them belonged to each of the three countries. Within each site, about $30 \%$ of health professionals belonging to the Bolivia and 
Table 2: Descriptive table of participants according to the completion with the course by socio-demographic characteristics

\begin{tabular}{|c|c|c|c|c|c|c|c|}
\hline & \multicolumn{2}{|c|}{ Overall } & \multicolumn{2}{|c|}{ Completed } & \multicolumn{2}{|c|}{ Not completed } & \multirow[t]{2}{*}{$p$-Valu } \\
\hline & $n$ & $\%$ & $n$ & $\%$ & $n$ & $\%$ & \\
\hline Overall & 292 & 100 & 171 & 58.6 & 121 & 41.4 & \\
\hline \multicolumn{8}{|l|}{ Country } \\
\hline Bolivia & 107 & 36.7 & 78 & 45.6 & 29 & 24.0 & \multirow[t]{3}{*}{0.000} \\
\hline Guatemala & 90 & 30.8 & 53 & 31.0 & 37 & 30.5 & \\
\hline Paraguay & 95 & 32.5 & 40 & 23.4 & 55 & 45.5 & \\
\hline \multicolumn{8}{|l|}{ Profession } \\
\hline Doctors & 113 & 54.3 & 87 & 51.8 & 26 & 65.0 & \multirow[t]{3}{*}{0.287} \\
\hline Nurses & 55 & 26.5 & 46 & 27.4 & 9 & 22.5 & \\
\hline Others & 40 & 19.2 & 35 & 20.8 & 5 & 12.5 & \\
\hline \multicolumn{8}{|l|}{ Sex } \\
\hline Men & 58 & 27.9 & 39 & 23.2 & 19 & 47.5 & \multirow[t]{2}{*}{0.046} \\
\hline Women & 150 & 72.1 & 129 & 76.8 & 21 & 52.5 & \\
\hline \multicolumn{8}{|l|}{ Age } \\
\hline$\leq 35$ years old & 106 & 51.0 & 86 & 51.2 & 20 & 50.0 & \multirow[t]{2}{*}{0.563} \\
\hline$>35$ years old & 102 & 49.0 & 82 & 48.8 & 20 & 50.0 & \\
\hline \multicolumn{8}{|l|}{ Smoking } \\
\hline Smokers & 25 & 12.0 & 19 & 11.3 & 6 & 15.0 & \multirow[t]{3}{*}{0.773} \\
\hline Former smokers & 29 & 14.0 & 23 & 13.7 & 6 & 15.0 & \\
\hline Never smokers & 154 & 74.0 & 126 & 75.0 & 28 & 70.0 & \\
\hline \multicolumn{8}{|l|}{ Previous training } \\
\hline Yes & 23 & 7.9 & 19 & 11.1 & 4 & 3.3 & \multirow[t]{2}{*}{0.015} \\
\hline No & 269 & 92.1 & 152 & 88.9 & 117 & 96.7 & \\
\hline
\end{tabular}

Completed, completed the 4 modules + exam; $p$-value, Chi-square test.

Guatemala sites enrolled in the course and only $12.7 \%$ of the professionals from Paraguay. Generally, the majority of them were doctors $(54.3 \%)$ and women $(72.1 \%)$ (Table 2$)$.

\section{Dose}

From all health professionals enrolled, $91.8 \%$ completed Module 1, 88.9\% Module 2, 87.0\% Module 3, $85.6 \%$ Module 4 and $58.6 \%$ completed all the modules and the exam. There were differences between those who completed the course and the baseline survey versus those who did not complete it in terms of country and previous training (Table 2 ).

Table 3 describes the characteristics of those health professionals who completed the course and the evaluation exam by country. We observe differences in the representation of health professional groups by country and sex. Thus, the majority of health professionals who completed the course from Bolivia were nurses $(44.7 \%)$, while in Guatemala and Paraguay they were doctors $(59.6 \%$ and $77.5 \%$, respectively). There is an important difference in terms of enrollment of men and women, as the number of female participants is more than twice that of male participants in both Bolivia and Paraguay. In addition, participants with higher scores in the final exam test were from Paraguay (mean $=84.5 \mathrm{SD}=12.1$ ) in comparison to Bolivia (mean $=79.3 \mathrm{SD}=15.2)$ and Guatemala (mean = 74.3 SD $=15.6)(p=0.007)$. Doctors obtained higher scores than nurses and other professionals, but the differences were not statistically significant.

\section{Satisfaction}

One hundred and thirty-four participants took part in the satisfaction survey, which obtained a high score in all their dimensions (from 4.4 to 4.7 out of a maximum score of 5).

\section{Qualitative}

This section describes the experiences of the participants based on six main topics that emerged through the exploration of responses to seven open-ended questions.

\section{Dissemination of the e-learning course and materials}

Most participants got the information on the program verbally through the local program coordinators, despite the 
Table 3: Descriptive table of health professionals who completed the course and the evaluation exam by country

\begin{tabular}{|c|c|c|c|c|c|c|c|c|c|}
\hline & \multicolumn{2}{|c|}{ Overall } & \multicolumn{2}{|c|}{ Bolivia } & \multicolumn{2}{|c|}{ Guatemala } & \multicolumn{2}{|c|}{ Paraguay } & \multirow[t]{2}{*}{$p^{*}$} \\
\hline & $n$ & $(\%)^{\mathrm{b}}$ & $n$ & $(\%)^{\mathrm{b}}$ & $n$ & $(\%)^{b}$ & $n$ & $(\%)^{b}$ & \\
\hline Overall $^{\mathrm{a}}$ & 171 & $(100)$ & 78 & $(45.6)$ & 53 & $(31)$ & 40 & $(23.4)$ & 0.001 \\
\hline \multicolumn{10}{|l|}{ Profession } \\
\hline Doctors & 87 & $(51.8)$ & 25 & $(32.9)$ & 31 & $(59.6)$ & 31 & $(77.5)$ & \multirow[t]{3}{*}{0.000} \\
\hline Nurses & 46 & $(27.4)$ & 34 & $(44.7)$ & 7 & $(13.5)$ & 5 & $(12.5)$ & \\
\hline Other & 35 & $(20.8)$ & 17 & $(22.4)$ & 14 & $(26.9)$ & 4 & $(10.0)$ & \\
\hline \multicolumn{10}{|l|}{ Sex } \\
\hline Men & 39 & $(23.2)$ & 12 & $(15.8)$ & 20 & $(38.5)$ & 7 & $(17.5)$ & \multirow[t]{2}{*}{$0.01 \mathrm{c}$} \\
\hline Women & 129 & $(76.8)$ & 64 & $(84.2)$ & 32 & $(61.5)$ & 33 & $(82.5)$ & \\
\hline \multicolumn{10}{|l|}{ Age } \\
\hline$\leq 35$ years old & 86 & $(51.2)$ & 29 & $(38.2)$ & 27 & $(51.9)$ & 30 & $(75.0)$ & \multirow[t]{2}{*}{0.045} \\
\hline$>35$ years old & 82 & $(48.8)$ & 47 & $(61.8)$ & 25 & $(48.1)$ & 10 & $(25.0)$ & \\
\hline \multicolumn{10}{|l|}{ Smoking } \\
\hline Smoker & 19 & $(11.3)$ & 11 & $(14.5)$ & 4 & $(7.7)$ & 4 & $(10.0)$ & \multirow[t]{3}{*}{0.075} \\
\hline Former smoker & 23 & $(13.7)$ & 9 & $(11.8)$ & 11 & $(21.2)$ & 3 & $(7.5)$ & \\
\hline Never smoker & 126 & $(75.0)$ & 56 & $(73.7)$ & 37 & $(71.1)$ & 33 & $(82.5)$ & \\
\hline \multicolumn{10}{|l|}{ Previous training } \\
\hline Yes & 19 & $(11.1)$ & 4 & $(5.1)$ & 5 & $(9.4)$ & 10 & $(25.0)$ & \multirow[t]{2}{*}{0.414} \\
\hline No & 152 & $(88.9)$ & 74 & $(94.9)$ & 48 & $(90.6)$ & 30 & $(75.0)$ & \\
\hline
\end{tabular}

a\% per row.

b\% per column.

"Chi-square test.

use of several means for disseminating the information, including emails, posters, flyers, text messages and presentations. In all cases the information provided was considered sufficient to inform them about registration procedures. They also reported having been given close follow-up by the coordination teams to successfully enroll.

Given that an electronic mailing account was necessary, participants who did not have one, were assisted by the coordination team members to open one.

We were invited via the internet, they sent us an email. Mr. XXX invited us to see if we wanted to participate or not. For the ones who did not have an email account, he created one.

\section{Motivation}

Participants noted three major sources of motivation (M):

M1: Content applicability. Participants appreciated the strong relationship between course content and their daily activities, and the interest in having an institutional policy regarding tobacco cessation. These factors were especially relevant for the professional groups (including medical doctors and other professionals), who also mentioned having another course to add to their continuing education history.
Professionally the program also motivated me because it is a practical method to approach the patient, sometimes we say many things and the patient only hears the first five minutes, it is a practical way to reach them and give them direct advice. It is an added value I have as a professional.

For me the main motivation was to have an international certification from the Catalan Institute of Oncology and that speaking the same language would help us.

M2: Online methodology and gratuity. Participants in all groups mentioned the flexibility of time and space as an advantage. However, some people mentioned that the amount of time they were given to complete the course was so long that they lost the thread and it was difficult to start over. The organizers, however, report that some participants were hostile to the verbal insistence to continue with the course.

The easiest part is to have access through a computer at any moment, not having to follow a specific schedule. I did it in the hospital because I am not very fond of technology and at home, I do not have time to sit on the computer.

M3: Personal factors. Personal factors included helping a loved one quit smoking, personal growth, and, 
having the opportunity to approach online methodology for the first time. This was especially common among nurses and personnel with lower educational levels.

It caught my attention because apart from the fact that I quit smoking, it helps me help other people, young people around me.

\section{Demotivation}

Technical difficulties. The main source of demotivation for all groups was the technical difficulties experienced throughout the course. All groups reported difficulties in accessing the portal, the need to retake modules repeatedly and the consequent extension of time taken to complete the course. Also, delays in receiving their password were mentioned and even upon receiving it, it did not always work. The registration process was perceived as unnecessarily long due to the initial questionnaire. The time frame to complete the course was not clear, which caused confusion in some cases.

Access and format of the information. Despite being an online course designed to work on tablets and cell phones, some participants pointed out that it only worked on computers and not on tablets or cell phones. When the platform worked on tablets, the interactive windows did not always work, causing people to read the information only partially. The audios were also difficult to hear.

I think the most difficult part for me was that I could not use my tablet. Because we only have one laptop in the house for five people, then it was complicated for me that everybody had to do homework, to do work and when they vacated it, I was already tired and did not want to do it. I also could not access all the material on the tablet, when the evaluation arrived, I would say "but I did not see that, where was it?" Because the windows do not open on the device.

The nursing personnel preferred to have the materials printed out. In Bolivia, the technician in charge facilitated printed copies. In Guatemala, although the printed material was available, few people found out and therefore had access to it. This lack of information reflects deficiencies in the communication between participants and organizers in Guatemala.

I felt that it was better to read on paper than from the computer, oftentimes I did not have credit (for an internet café or cellphone), and so if I already had the photocopies it was better.

Methodology and technical resources. Regarding the familiarity of participants with computer use and online courses, most participants reported using electronic devices frequently, predominantly smart phones. The nursing staff was the least familiar with computers and from this group, the only people who do not have a computer at home were reported. In these cases, they took the course in the computer lab at the hospital or at an Internet cafe near their places of residence. In the groups of professionals and doctors, everyone mentioned using the computer frequently in their daily lives. In this case, the majority took the course outside the hospital, except for people who do not consider themselves proficient in computer use.

Technical support was important for overcoming the lack of familiarity with e-learning courses and may explain why some groups were more successful than others across sites. In Bolivia, for instance, there was a person in charge of helping participants in navigating the course. His support, however, was not only technical. He formed a WhatsApp group in which he motivated participants to keep moving along the modules and sent reminders during the week. This created a sense of community, especially among nurses, which resulted in high completion rates.

Despite the technical difficulties experienced, the notion that online methodology favored people in terms of flexibility prevailed. Regarding the modes of presenting the information, the nurses reported that the use of case studies was useful to remember information, since it allowed for the humanization of the previously studied content. Also, due to the course dynamics, in case of questions, people could return and verify if the correct answers were the ones that were initially picked.

Content applicability. All the groups considered the e-learning course useful and applicable, professionally and personally. For the nurses, the most relevant information regarded the direct interventions they can perform with patients and families. The professional group was mostly interested in both the diagnostic tools and motivation to quit smoking, as well as the intervention strategies provided. The medical doctors indicated that the most relevant information regarded placing patients at a certain level of smoking. All the groups reported having little information about smoking and how to approach smoking patients and devoting little time to the matter, although they recognized its relevance. The only unit where the issue is addressed is radiation therapy, due to the combined effects of radiation therapy and smoking. In the case of personnel in the palliative care area, they mentioned that due to the nature of the work they do with patients, at the point where people arrive at this unit, continuing to smoke or not will make little 
difference for patients and may even generate family and personal conflicts.

Personally, I did not know the medications that were mentioned here. For me it was very useful because now I know that, I have that (knowledge). I think it is our obligation to guide the patient and we have to get involved and at least tell them what can be done, even if we do not have, at that moment, a (specialized) clinic or a place to refer patients.

Future directions. The different groups believe that the applicability of the content of the course should be turned into specific actions locally, individually and institutionally. The proposed actions range from becoming an anti-tobacco bastion by disseminating the information acquired, to the establishment of a tobacco clinic that would aid in the mainstreaming of the anti-tobacco agenda into each of the different units of the hospitals. By having an institutional policy regarding tobacco consumption, protocols can be designed to implement coordinated actions among all the different levels of attention and improve the effectiveness of the intervention.

The challenge this course poses does not end here, getting the certificate, but we need to contribute with this to society, because that is the biggest challenge and the biggest goal. Let us be spokespersons before our families and the community, so that this habit may disappear and reduce its impact on health. So, as a nurse, what am I going to say to the community to reduce that impact?

\section{Suggestions}

The nurses believe that the content of the course could be adapted to the tasks carried out by different professionals within the hospital. For instance, the course content for doctors could be focused on treatment prescription, while the course content for nurses could be more focused on cognitive or behavioral strategies and following up on treatments prescribed by doctors. However, the whole group acknowledges that the contents are very applicable to their work context and how they can be transferred to another context as preventive measures. Delivering printed materials is seen as a way of minimizing the technical difficulties associated with an online platform. The correct functioning of the elearning program on tablets or cellular devices was also seen as a way of improving access.

Even though the phrasing of the material was revised locally before the implementation, participants in all groups mentioned having difficulties understanding them due to lack of cultural pertinence.
The group of organizers suggested the use of incentives and institutional pressure to enforce course completion, as well as having a tutor that can follow-up students at different stages. As for the platform, they proposed to make it much simpler, reducing the pop-up windows and generating a more intuitive interface. This group also proposed to locally manage each platform to avoid delays in provision of passwords and to avoid technical problems that arise due to the time difference between Spain and the three countries.

\section{Reasons for not participating or completing the process}

Participants that did not take the online course after having signed up for it, reported technical difficulties as the main reason for non-completion, including delays in getting their password and not being able to use their cellular phones and tablets to access the material. Others reported having no time to devote to the course even if they considered that the information was necessary for their daily activities. Participants that did not sign up for the course reported not having enough information regarding the dates and other details on how to access the material.

Some participants finished all the modules but did not complete the final exam. Technical difficulties were reported as one of the causes for not finishing the process. Difficulties in understanding the questions were also reported, as well as differences in difficulty levels between the modules and the exam. The fact that the questions were analysis and not content based, presented a challenge for some people.

Some questions were difficult to understand, we could not interpret the question even if we read it over and over again.

I believe the course was easy and simple, and the information was easy to assimilate, but the evaluation was very difficult. Even at our level (medical doctors), there were some questions that were very complicated.

Other reasons for not completing the evaluation were attitudinal. In some cases, the evaluation process itself was challenging for some participants, as they feared they would get a bad grade. Others report they did not think the evaluation was important, so they did not put enough effort into the exam as they should have.

Specifically, it was in the exam, in the final evaluation, we were afraid of making mistakes and that the performance would drop because those grades remained. 


\section{DISCUSSION}

Our results reveal the challenges of implementing tobacco cessation programs in LMICs from the Latin American Region through an e-learning platform. From this pilot study, we gained experience and learned important lessons that could be of interest for future elearning projects in these countries. First, the process of spreading new learning approaches needs cultural and content adaptation that implies reviewing whether the material, the examples, and the language, are pertinent to the new target group (Wang-Schweig et al., 2014). Second, e-learning courses in health organizations should encompass several dissemination strategies to reach a wide range of audiences (doctors, nurses, others). Among the diversity of strategies used, invitations through email worked better with doctors, and personal invitations from key persons from the organization increased the participation and engagement of nurses and other health professionals. Third, health professionals from LMIC present a high inter-professional difference in terms of motivation and commitment to finishing the online course; thus, while doctors were used to undertake online courses and finishing them, nurses and support staff expressed difficulties in enrolling to the online platform and manifested their preference to have a mixed methodology in which they can use an online platform, but at the same time, printed materials to use when they do not have access to a computer. We observed that this group had less experience with the use of computers and many of them did not have a personal tablet or computer in their home so they were only able to log on into the course by using the technological resources provided by the hospitals. Nevertheless, the experience of the Fruitful Project (Martínez et al., 2017a,b) may be a starting point in the process of undertaking more e-learning programs to LMIC to offer education solutions with the use of emerging and growing communication technologies.

We found that a high proportion of healthcare professionals completed the four modules of the e-learning program. However, the completion of all the modules and the exam was lower than expected in comparison to health professionals who did the same e-learning smoking cessation program in Catalonia (Spain) (Martínez et al., 2019). Doctors and participants from Bolivia had higher rates of completion, including the modules and taking the test, compared to the other two countries. We also found a significantly greater proportion of participants who completed the training when online skills were reported, or external help provided. For instance, in Bolivia, an information technology (IT) technician supported health professionals, which resulted in higher dose to training completion. In addition, a deficient technology access and problems with the log in of the platform were reported as a barrier. Other factors that could explain the dose of the course were learner motivation, leadership engagement, internal communication and IT support. After the release of the course, several strategies were also put in place to promote a higher dose such as personalized email messages, reminder videos on the platform, messages, in person sessions and contests to celebrate the World No-Tobacco Day.

Our results are in line with the diffusion of innovation literature that posits that the implementation of a program is a function of several factors, including the perceived need to do things differently (Durlak and DuPre, 2008). In addition, it has been demonstrated-in research conducted in high-income countries-that several contextual and organizational factors could affect the implementation outcomes including: leadership and organizational commitment, and individual participant factors, such as job role and scope (Park et al., 2018). Unfortunately, there is a lack of online training programs tested and evaluated in LMIC (Winters et al., 2019). However, in these countries it is especially relevant to explore these factors qualitatively to learn which factors could help to understand the adoption of an innovation, its sustainability and diffusion. In our case, several suggestions have been given to improve the future diffusion such as providing technical support and adapting the material to their work responsibilities.

Tobacco use is rapidly increasing in low-income LACs such as Bolivia, Guatemala and Paraguay (Mayor, 2009). Online education in tobacco cessation might be the solution to provide evidence-based treatment for tobacco dependence in these countries (Selby et al., 2015; Ye et al., 2018). Mainly, because online education reaches many learners each time, it is cost-efficient, and can reach remote locations (Winters et al., 2019). However, e-learning programs also require devices for its use-mainly computers-and high-speed Internet connection. Use of these devices and Internet quality are rapidly growing in low-income countries (Pew Research Center, 2015). However, the quality of the service was a main barrier and source of demotivation, especially in Guatemala.

Another factor that influenced the dose of the training was the experience with the use of the Internet known as 'e-readiness', which varied among learners mainly due to the variability of cultural backgrounds, disciplines and prior academic qualifications. A study conducted in Guatemala on hand hygiene showed that medical doctors presented higher e-readiness scores than 
nurses (Gonzalez et al., 2016). In addition, factors associated with e-readiness (access to a fairly new computer, Internet skills, use of the computer several times a week and communication skills using online technologies) have been associated with successful course completion (Gonzalez et al., 2016). In our case, successful course completion has been associated with higher educational levels, having participated previously in e-learning courses, and having technical support available. In addition, the figure of a coordinator, who supports the students in navigating the course and handles the administrative aspects of the training locally, shows potential in reducing the drop-out rates due to lack of ereadiness.

Evidence in the literature suggests that e-learning is a useful tool for overcoming barriers to access for health professions' training (Barteit et al., 2019). However, providing an e-learning platform is just the first step. Other limitations related to e-learning are the quality of the bandwidth, which often contributed to slow speed and low quality of videos or visual outputs, difficulties reading or watching content from a computer screen, slow downloading speed, inadequate computer facilities, limited access to computers and frequent electrical failures (Frehywot et al., 2013). These factors have been pointed out as important threats for participants' motivation for improving their continuing education (Färnman et al., 2016; Protsiv et al., 2016). In these contexts, the basic conditions for a successful implementation need to be secured by the institution by providing, for instance, enough computers and equipment to increase access. Also, providing different means to get the materials, such as printing them out so that participants who do not have access to a computer at home can still read the material. This may reduce dissatisfaction and increase course dose. Given that the workload of health professionals may impede the dedication needed to complete the course (Mendoza Montano, 2016), providing a short time during the workday to engage with the elearning platform may also prevent burdening the staff even more. This will be especially important to increase the likelihood of completion for those health workers who do not possess a computer at home.

While the majority of e-learning health courses have been addressed to Medical Universities to train future physicians (Liu et al., 2016), only a small proportion have been focused on specific continuous medical education (Frehywot et al., 2013; Liu et al., 2016). Our e-learning program, however, addressed all health professionals within the participant organizations to obtain an overall penetration of the learning gained and work transversally on smoking cessation. Our qualitative evaluation shows, however, that the motivation sources for physicians, nurses and other professionals might be slightly different and that the skills with which participants begin their training impacts their perceptions on barriers and benefits of the course. Learning styles may also vary widely due to educational and personal characteristics, which highlights the need to adapt materials in terms of content and structure, which may not be possible in this format (Hortsch, 2015).

Institutional support is critical in sustaining an elearning program (Barefield and Meyer, 2013). Our study supports the need for institutional involvement, the participation of stakeholders in the design process, and dedication from the implementation teams. It also highlights the need for flexibility beyond the design phase, as different institutions may present different challenges and needs at different stages. However, efficient communication channels, support for the students and institutional commitment and awareness, are the cornerstone of successful implementation. Our evaluation demonstrates that partnership with a high-income country with similar background and language is an asset for achieving the correct implementation of e-learning training in LMICs. Speaking the same language, however, does not guarantee a perfect match. In these cases, the translation of one context to another needs to consider local idiosyncratic characteristics and linguistic variation. Our exploration, in general, evidences the feasibility of e-learning projects as a means for providing medical training in the region. Our experience highlights that flexibility and adaptability are key to overcoming barriers to successful project implementation across settings, even if this means losing the possibility of one to one comparison. As suggested in a recent review, implementation of interventions and the introduction of innovations in low-income countries frequently thrive under constraints, but collaborative research (between lowand high-income countries) is an opportunity to overcome the difficulties and link organizations globally on common health problems (Yapa and Bärnighausen, 2018). Given that low-income countries lack resources to produce their own material, they should benefit from the possibility of adapting and testing evidence-based programs, created in other contexts, to improve services and practices in their deprived healthcare systems.

\section{Limitations}

Our study had several limitations. First, the sample size was relatively small, and because we conducted the study in a single center per country, we do not have the possibility of comparing results within each country. 
Second, we included specific hospitals (two devoted to oncology and one to respiratory), which are very sensitive to tobacco-related diseases. So, generalizability of manager, coordinator and health worker motivation could differ in relation to other types of health centers.

In addition, health professionals from the three countries were invited to voluntarily participate in the project. Thus, whether the recruitment process applied by each coordinator affected both the number of participants recruited and the commitment to start and finish on time, remains an open question. In this sense, the whole process was adapted to the leadership styles and installed capacity at each site, which led to very different managerial decisions and experiences. Moreover, we were not able to conduct a qualitative study in Paraguay due to difficulties in finding a qualitative researcher willing to perform the focus group phase. Finally, although we did not include elements to measure the e-readiness, we gained insight into the strengths and limitations of our project through the experiences of participants.

\section{CONCLUSIONS}

Our results report the challenges and the opportunities of implementing an e-learning program in LMIC, showing that this model of education is possible but needs to consider in advance how to overcome the possible roadblocks that could jeopardize students' motivation to undertake the course and engagement to complete it. From our experience we learned the need to offer technological resources (such as computers and appropriate bandwidth), technical support (by an informatic facilitator) and effective communication channels (emails, posters, personal invitation). In addition, the role of key persons who act as champions in healthcare organizations in LMIC organizations is key in generating dynamism and engagement in an organizational project that implicates innovation and training.

\section{AUTHORS' CONTRIBUTIONS}

Dr Martinez conceived and is the PI of the project and prepared the contents of the e-learning course and Dr Fernández and Dr Company have co-designed the study. O. Guillen gave technical support with the online platform. Dr Vides-Porras was the consultant of the focus groups in Guatemala and created the script for the interview with Dr Martínez. Dr Vides-Porras and Dr Martínez drafted the first version of the manuscript. Finally, Dr Arrien and Dr Cáceres were the project leaders in their countries.

\section{ACKNOWLEDGMENTS}

In my memorial to our colleague Dr Paula Cáceres who passed away in October 2018.

\section{FUNDING}

This study was funded by Global Bridges Mayo Clinic (Pfizer Medical Group; GB-13520139: Development and Dissemination of a Tobacco Cessation Training Program for Healthcare Professionals in Spanish-speaking Countries).

\section{ETHICAL CONSIDERATIONS}

All participants were informed about the main objectives of the study and provided informed consent for their voluntary participation. This study protocol was approved by the Ethics Committee of the Hospital Universitari de Bellvitge (PR338/ 15).

\section{REFERENCES}

Abutarbush, S. M., Naylor, J. M., Parchoma, G., D’Eon, M., Petrie, L., Carruthers, T. et al. (2006) Evaluation of traditional instruction versus a self-learning computer module in teaching veterinary students how to pass a nasogastric tube in the horse. Journal of Veterinary Medical Education , 33, 447-454.

Aggarwal, R., Gupte, N., Kass, N., Taylor, H., Ali, J., Bhan, A. et al. (2011) A comparison of online versus on-site training in health research methodology: a randomized study. BMC Medical Education, 11, 37-6920-11-37.

Barefield, A. C. and Meyer, J. D. (2013) Leadership's role in support of online academic programs: implementing an administrative support matrix. Perspectives in Health Information Management, 10, $1 \mathrm{f}$.

Barteit, S., Jahn, A., Banda, S. S., Bärnighausen, T., Bowa, A., Chileshe, G. et al. (2019) e-Learning for medical education in sub-Saharan Africa and low-resource settings: viewpoint. Journal of Medical Internet Research, 21, e12449.

Bello, S., Soto, M., Michalland, S. and Salinas, J. (2004) A national survey on smoking habit among health care workers in Chile. Revista Medica de Chile, 132, 223-232.

Brooks, H. L., Pontefract, S. K., Vallance, H. K., Hirsch, C. A., Hughes, E., Ferner, R. E. et al. (2016) Perceptions and impact of mandatory eLearning for foundation trainee doctors: a qualitative evaluation. PLoS One, 11, e0168558.

Campbell, S., Pieters, K., Mullen, K. A., Reece, R. and Reid, R. D. (2011) Examining sustainability in a hospital setting: case of smoking cessation. Implementation Science, 6, 108.

Card, J. J., Solomon, J. and Cunningham, S. D. (2011) How to adapt effective programs for use in new contexts. Health Promotion Practice, 12, 25-35.

Carson, K. V., Verbiest, M. E., Crone, M. R., Brinn, M. P., Esterman, A. J. and Assendelft, W. J. et al. (2012) Training 
health professionals in smoking cessation. Cochrane Database of Systematic Reviews, 5, CD000214.

Cheng, B., Wang, M., Mørch, A. I., Chen, N. S., Kinshuk, J. and Michael, S. (2014) Research on e-learning in the workplace 2000-2012: a bibliometric analysis of the literature. Educational Research Review, 11, 56-72.

Denzin, K. and Lincoln, Y. (2018) Handbook of Qualitative Research. SAGE, Los Angeles, CA.

Durlak, J. A. and DuPre, E. P. (2008) Implementation matters: a review of research on the influence of implementation on program outcomes and the factors affecting implementation. American Journal of Community Psychology, 41, 327-350.

Färnman, R., Diwan, V., Zwarenstein, M. and Atkins, S. (2016) Successes and challenges of north-south partnerships-key lessons from the African/Asian Regional Capacity Development projects. Global Health Action, 9, 30522.

Fossey, E., Harvey, C., Mcdermott, F. and Davidson, L. (2002) Understanding and evaluating qualitative research. Australian \& New Zealand Journal of Psychiatry, 36, 717-732.

Frehywot, S., Vovides, Y., Talib, Z., Mikhail, N., Ross, H., Wohltjen, H. et al. (2013) e-Learning in medical education in resource constrained low- and middle-income countries. Human Resources for Health, 11, 4-4491-11-4.

Friesen, N. (2009) Chapter two: narrative: the storied multiplicity of e-learning research. Counterpoints, 333, 23-44.

Gonzalez, M. L., Melgar, M., Homsi, M., Shuler, A., AntillonKlussmann, F., Matheu, L. et al. (2016) Measuring readiness for and satisfaction with a hand hygiene e-learning course among healthcare workers in a paediatric oncology centre in Guatemala City. International Journal of Infection Control, 12, pii: 16072 .

Gordon, J. S., Mahabee-Gittens, E. M., Andrews, J. A., Christiansen, S. M. and Byron, D. J. (2013) A randomized clinical trial of a web-based tobacco cessation education program. Pediatrics, 131, e455-462.

Hortsch, M. (2015) "How we learn may not always be good for us"-do new electronic teaching approaches always result in better learning outcomes? Medical Teacher, 37, 507-509.

Jennifer, G., Susan, M. and Jennifer, R. (2007) e-Learning: the student experience. British Journal of Educational Technology, 38, 560-573.

Kassel, J. D. and Ross, H. (2005) The role of training in global tobacco control research. American Journal of Public Health, 95, 946-949.

Krueger, R. A. (2015) Focus Groups: A Practical Guide for Applied Research. Sage Publication, Los Angeles, CA.

Liu, Q., Peng, W., Zhang, F., Hu, R., Li, Y. and Yan, W. (2016) The effectiveness of blended learning in health professions: systematic review and meta-analysis. Journal of Medical Internet Research, 18, $\mathrm{e} 2$.

Martínez, C., Castellano, Y., Andres, A., Fu, M., Antón, L., Ballbè, M. and Fernández, E. (2017a) Factors associated with implementation of the 5A's smoking cessation model. Tobacco Induced Diseases, 15, 1-11.
Martínez, C., Castellano, Y., Andrés, A., Fu, M., Feliu, A., Antón, L. et al. (2019) Impact of an online training program in smoking cessation interventions in hospitals. Journal of Nursing Scholarship, 51, 449-458.

Martínez, C., Company, A., Guillen, O., Margalef, M., Arrien, M. A., Sánchez, C. et al. (2017b) Adaptation, Implementation plan, and evaluation of an online tobacco cessation training program for health care professionals in three Spanish-speaking Latin American countries: protocol of the fruitful study. JMIR Research Protocols, 6, e7.

Mayor, S. (2009) Tobacco atlas illustrates shift to low income countries. $B M J, 338$, b981

Mendoza Montano, C., Fort, M., deRamirez, M., Cruz, J. and Ramirez-Zea, M. (2016) Evaluation of a pilot hypertension management programme for Guatemalan adults. Health Promotion International, 31, 363-374.

Morse, J. M. (2003) Principles of mixed methods and multi-method research design. In Teddlie, C. and Tashakkori, A. (eds), Handbook of Mixed Methods in Social and Behavioral Research, Sage Publication, Thousand Oaks, CA, pp. 189-208.

Moore, D. E., Jr , Green J. S. and Gallis, H. A. (2009) Achieving desired results and improved outcomes: integrating planning and assessment throughout learning activities. The Journal of Continuing Education in the Health Professions, 29, $1-15$.

Moore, G. F., Audrey, S., Barker, M., Bond, L., Bonell, C., Hardeman, W. et al. (2015) Process evaluation of complex interventions: Medical Research Council guidance. BMJ, 350, h1258

Muller, F. and Wehbe, L. (2008) Smoking and smoking cessation in Latin America: a review of the current situation and available treatments. International Journal of Chronic Obstructive Pulmonary Disease, 3, 285-293.

Organización Panamericana de la Salud (OPS). (2014) Informe Sobre Control del Tabaco para la Región de las Américas. OPS, Washington, DC.

Park, J. S., Moore, J. E., Sayal, R., Holmes, B. J., Scarrow, G., Graham, I. D. et al. (2018) Evaluation of the "Foundations in Knowledge Translation" training initiative: preparing end users to practice KT. Implementation Science, 13, 63.

Pew Research Center. (2015) Internet Seen as Positive Influence on Education But Negative Influence on Morality in Emerging and Developing Nations. https://www.pewre search.org/global/2015/03/19/1-communications-technol ogy-in-emerging-and-developing-nations/ (last accessed 20 April 2018).

Ponciano-Rodriguez, G. (2010) The urgent need to change the current medical approach on tobacco cessation in Latin America. Salud Pública de México, 52(Suppl. 2), S366-372.

Proctor, E., Silmere, H., Raghavan, R., Hovmand, P., Aarons, G., Bunger, A. et al. (2011) Outcomes for implementation research: conceptual distinctions, measurement challenges, and research agenda. Administration and Policy in Mental Health and Mental Health Services Research, 38, 65-76. 
Protsiv, M., Atkins, S and ARCADE Consortium. (2016) The experiences of lecturers in African, Asian and European universities in preparing and delivering blended health research methods courses: a qualitative study. Global Health Action, $9,28149$.

Rogers, E. M. (2003) Diffusion of Innovations, 5th edition. Free Press, New York, NY.

Salinas, J., Munoz, C., Albagli, A., Araya, G. and Vio, F. (2017) The contribution of distance education to health promotion in Chile. Health Promotion International, 32, 913-921.

Sarna, L. P., Bialous, S. A., Kraliková, E., Kmetova, A., Felbrová, V., Kulovaná, S. et al. (2014) Impact of a smoking cessation educational program on nurses' interventions. Journal of Nursing Scholarship, 46, 314-321.

Schmelz, A. N., Nixon, B., McDaniel, A., Hudmon, K. S. and Zillich, A. J. (2010) Evaluation of an online tobacco cessation course for health professions students. American Journal of Pharmaceutical Education, 74, 36.

Selby, P., Goncharenko, K., Barker, M., Fahim, M., Timothy, V., Dragonetti, R. et al. (2015) Review and evaluation of online tobacco dependence treatment training programs for health care practitioners. Journal of Medical Internet Research, 17, e97.

Toll, B. A., Rojewski, A. M., Duncan, L. R., Latimer-Cheung, A. E., Fucito, L. M., Boyer, J. L. et al. (2014) "Quitting smoking will benefit your health": the evolution of clinician messaging to encourage tobacco cessation. Clinical Cancer Research, 20, 301-309.
Tong, V. T., Turcios-Ruiz, R. M., Dietz, P. M. and England, L. J. (2011) Patterns and predictors of current cigarette smoking in women and men of reproductive age-Ecuador, El Salvador, Guatemala, and Honduras. Revista Panamericana de Salud Pública, 30, 240-247.

Wang-Schweig, M., Kviz, F. J., Altfeld, S. J., Miller, A. M. and Miller, B. A. (2014) Building a conceptual framework to culturally adapt health promotion and prevention programs at the deep structural level. Health Promotion Practice, 15, $575-584$.

WHO. (2011) Health Indicator. https://apps.who.int/infobase/ Indicators.aspx (last accessed 1 March 2014, 2017).

Winters, N., Langer, L., Nduku, P., Robson, J., O’Donovan, J., Maulik, P. et al. (2019) Using mobile technologies to support the training of community health workers in low-income and middle-income countries: mapping the evidence. BMJ Global Health, 4, e001421.

World Health Organization. (2013) WHO Report on the Global Tobacco Epidemic.

Yapa, H. M. and Bärnighausen, T. (2018) Implementation science in resource-poor countries and communities. Implementation Science, 13, 1-13.

Ye, L., Goldie, C., Sharma, T., John, S., Bamford, M., Smith, P. M. et al. (2018) Tobacco-nicotine education and training for health-care professional students and practitioners: a systematic review. Nicotine \& Tobacco Research, 20, 531-542.

Zack, E. (2002) Smoking withdrawal and prolonged hospitalization. Clinical Journal of Oncology Nursing, 6, 7-11. 